\title{
Arbitrary precision value overlay and alignment system by double positioning of mask and wafer and electronic datum and nano sensor (notice of removal)
}

Wynn Bear, Xiang-Wen Xiong

Wynn L. Bear, Xiang-Wen Xiong, "Arbitrary precision value overlay and alignment system by double positioning of mask and wafer and electronic datum and nano sensor (notice of removal)," Proc. SPIE 7272, Metrology, Inspection, and Process Control for Microlithography XXIII, 727249 (24 March 2009); doi: 10.1117/12.816903 


\section{Arbitrary precision value overlay and alignment system by double positioning of mask and wafer and electronic datum and nano sensor (notice of removal)}

Proc. SPIE 7272, 727249 (2009); http://dx.doi.org/10.1117/12.816903

Online Publication Date: 23 February 2009

Retracted from Publication: 23 March 2009

Conference Date: Monday 23 February 2009

Conference Location: San J ose, California, USA

Conference Title: Metrology, Inspection, and Process Control for Microlithography XXIII

Conference Chairs: John A. Allgair, Christopher J. Raymond

Wynn L. Bear

Wynnbear leading lithography Inc. (USA)

Xiang-Wen Xiong

Wynnbear International DP and EUV lithography Inc. (China)

This paper (SPIE Paper 727249) was removed from the SPIE Digital Library on 30 April 2009 upon learning that the two names associated with this publication record, Xiang-Wen Xiong and Wynn L. Bear, are actually the same individual and not two different authors. This is not sanctioned by SPIE. As stated in the SPIE Guidelines for Professional Conduct and Publishing Ethics, "SPIE considers it the professional responsibility of all authors to ensure that the authorship of submitted papers properly reflects the contributions and consent of all authors." A serious violation of these guidelines is evident in this case. It is SPIE policy to remove papers from the SPIE Digital Library where serious professional misconduct has occurred and to impose additional sanctions as appropriate. 